\title{
Pomegranate (Punica granatum): a natural source for the development of therapeutic compositions of food supplements with anticancer activities based on electron acceptor molecular characteristics
}

\author{
Veljko Veljkovic $^{1,2}$, Sanja Glisic ${ }^{2}$, Vladimir Perovic ${ }^{2}$, Nevena Veljkovic ${ }^{2}$, Garth L Nicolson ${ }^{3}$ \\ ${ }^{1}$ Biomed Protection, Galveston, TX, USA; ${ }^{2}$ Center for Multidisciplinary Research, University of \\ Belgrade, Institute of Nuclear Sciences VINCA, P.O. Box 522, 11001 Belgrade, Serbia; \\ ${ }^{3}$ Department of Molecular Pathology, The Institute for Molecular Medicine, Huntington Beach, \\ CA 92647 USA
}

Corresponding author: Garth L Nicolson, PhD, MD (H), Department of Molecular Pathology, The Institute for Molecular Medicine, Huntington Beach, CA 92647 USA

Submission Date: October 3, 2016, Accepted Date: December 18, 2016, Publication Date: December 30, 2016

Citation: Veljkovic V.V., Glisic S., Perovic V., Veljkovic N., Nicolson G.L.. Pomegranate (Punica granatum): a natural source for the development of therapeutic compositions of food supplements with anticancer activities based on electron acceptor molecular characteristics. Functional Foods in Health and Disease 2016; 6(12):769-787

\begin{abstract}
Background: Numerous in vitro and in vivo studies, in addition to clinical data, demonstrate that pomegranate juice can prevent or slow-down the progression of some types of cancers. Despite the well-documented effect of pomegranate ingredients on neoplastic changes, the molecular mechanism(s) underlying this phenomenon remains elusive.

Methods: For the study of pomegranate ingredients the electron-ion interaction potential (EIIP) and the average quasi valence number (AQVN) were used. These molecular descriptors can be used to describe the long-range intermolecular interactions in biological systems and can identify substances with strong electron-acceptor properties. In this study, candidate human proteins interacting with pomegranate flavonoids have been analyzed by the informational spectrum method (ISM). This represents a virtual spectroscopy method for studying protein molecular interactions.
\end{abstract}

Results: Our analysis indicates that the anti-cancer properties of pomegranate juice can be ascribed to the strong electron-acceptor properties of its chemical ingredients. This analysis also 
suggests that pomegranate flavonoids inhibit the "NF-kappaB" (NF-kB) pathway, which plays a critical role in the pathogenesis of cancer.

Conclusion: The results offer a possible explanation for an important molecular mechanism underlying the anticancer activity of pomegranate ingredients, which could also serve as a basis for the development of new therapeutic compositions of food supplements with pomegranatelike anticancer properties.

Key words: cancer, pomegranate, flavonoids, food supplement, informational spectrum method

\section{BACKGROUND}

With more than 10 million new cases world-wide reported each year, cancer is one of the most devastating human diseases [1]. Despite progress in the understanding and treatment of these diseases including significant improvements in diagnostics and therapy based on applications of modern technology, the incidence and cure rates of various cancers, even in highly developed countries, have not improved significantly [2]. For this reason, increased attention has turned to complementary therapies, including natural dietary supplements. Among these natural agents, pomegranate (Punica granatum) juice has drawn a great deal of attention from both the scientific community and the general public due to its demonstrated ability to suppress cancers [3-13]. For example, pomegranate has been found to possess well-documented cancer chemopreventive and chemotherapeutic effects against prostate cancer [10-13]. The results of a Phase II clinical study of patients with rising prostate-specific antigen (PSA) levels following surgery or radiation for prostate cancer demonstrated that pomegranate juice produced statistically significant prolongation of PSA doubling times, suggesting that pomegranate consumption may retard prostate cancer progression [14].

Despite numerous published results of in silico, in vitro and in vivo studies of pomegranate, several questions remain, including which components of this dietary agent are responsible for these anti-cancer activities and by what mechanism do they actually suppress cancers. Analysis of the electronic properties of 101 pomegranate ingredients revealed that nearly $50 \%$ of these compounds represent potentially carcinostatic substances with strong electron-acceptor properties. Bioinformatics analysis of human proteins representing candidate targets for flavonoid ingredients of pomegranate was carried out in the present research to identify possible mechanisms through which flavonoids might inhibit the "NF-kappaB" (NF-кB) pathway. The results may aid in the development of new therapeutic compositions of food supplements with pomegranate-like anticancer activities.

\section{METHODS}

\section{Databases}

For analysis of the distribution of organic molecules according to their electronic properties, the PubChem compound database (PubChem) [15] and the NCI Natural Products Repository Extracts database (NPRE) [16] were used. For bioinformatics analysis of human proteins, the 
Universal Protein Resource database (UniProt) was utilized. This database represents the world's most comprehensive catalog of information on proteins, which was created by joining the information contained in Swiss-Prot, TrEMBL, and PIR databases [17].

Electron-ion interaction potential (EIIP) and average quasivalence number (AQVN) concepts

The intermolecular interactions in biological systems encompass two basic steps: (i) specific long-distance targeting of interacting molecules and (ii) chemical bond formation between interacting molecules. The first step is determined by selective long-range forces that are efficient at a distance longer than one linear dimension of the interacting macromolecules $\left(10^{2}-\right.$ $10^{3} \AA$ Á) [18-20]. These forces directly influence the number of productive collisions between interacting molecules. Before chemical bond formation can take place, reacting molecular

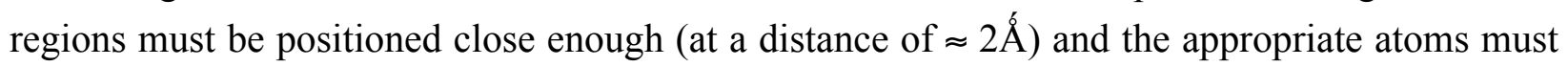
be held in the correct orientation for a successful reaction to follow. Additionally, the attractive forces involved in the recognition and binding of molecules must include all of the weak noncovalent forces (van der Waals, hydrogen bonding, ionic interactions, etc.). For this reason, stereochemical complementarity between interacting molecules is essential for the second step.

It has been proposed that the number of valence electrons and the EIIP representing the main energy term of valence electrons are essential physical parameters that determine the long-range properties of biological molecules [21]. We previously found [21, 22] that EIIP can be determined for organic molecules by the following simple equation derived from the "general model pseudopotential" [23-25],

$$
W=0.25 \frac{Z^{*} \sin \left(1.04 \pi Z^{*}\right)}{2 \pi}
$$

where $Z^{*}$ is the average quasivalence number (AQVN) determined by

$$
Z^{*}=\frac{1}{N} \sum_{i=1}^{m} n_{i} Z_{i}
$$

where $Z_{i}$ is the valence number of the $i$-th atomic component, $n_{i}$ is the number of atoms of the $i$ th component, $m$ is the number of atomic components in the molecule, and $\mathrm{N}$ is the total number of atoms. The EIIP values calculated according to equations (1) and (2) are in Rydbergs (Ry). A strong connection has been demonstrated between EIIP and AQVN of organic molecules and their biological activity (mutagenicity, carcinogenicity, toxicity, antibiotic, cytostatic, and antiviral activity) [21, 22, 27-29].

\section{Informational spectrum method (ISM)}

The informational spectrum method (ISM) is based on a model of the primary structure of a protein using a sequence of numbers, by assigning to each amino acid a defined parameter describing a physico-chemical property involved in the biological activity of the protein [30]. These values correspond to the EIIP [23-25], and this value determines the electronic properties of amino acids that are responsible for their intermolecular interactions [21]. The values of the EIIP for amino acids are given in Table 1. 
Table 1. The electron-ion interaction potential (EIIP) used to encode amino acids.

\begin{tabular}{cc}
\hline Amino acid & EIIP $[\mathrm{Ry}]$ \\
\hline Leu & 0.0000 \\
Ile & 0.0000 \\
Asn & 0.0036 \\
Gly & 0.0050 \\
Glu & 0.0057 \\
Val & 0.0058 \\
Pro & 0.0198 \\
His & 0.0242 \\
Lys & 0.0371 \\
Ala & 0.0373 \\
Tyr & 0.0516 \\
Trp & 0.0548 \\
Gln & 0.0761 \\
Met & 0.0823 \\
Ser & 0.0829 \\
Cys & 0.0829 \\
Thr & 0.0941 \\
Phe & 0.0946 \\
Arg & 0.0959 \\
Asp & 0.1263 \\
\hline &
\end{tabular}

The calculated numerical sequence, representing the primary structure of a protein, is then subjected to a discrete Fourier transformation, which is defined as follows:

$$
X(n)=\sum_{m=1}^{N} x(m) e^{-i 2 m(m-1) / N}, \quad n=1,2, \ldots, N / 2
$$

where $\mathrm{x}(\mathrm{m})$ is the $\mathrm{m}$-th member of a given numerical series, $\mathrm{N}$ is the total number of points in this series, and $\mathrm{X}(\mathrm{n})$ are discrete Fourier transformation coefficients. These coefficients describe the amplitude, phase, and frequency of sinusoids that comprised the original signal. The absolute value of complex discrete Fourier transformation defines the amplitude spectrum and the phase spectrum. The complete information about the original sequence is contained in both spectral functions. However, in the case of protein analysis, relevant information is presented in an energy density spectrum [30-32], which is defined as follows:

$$
S(n)=X(n) X^{*}(n)=|X(n)|^{2}, n=1,2, \ldots, N / 2
$$

In this way, sequences are analyzed as discrete signals. It is assumed that their points are equidistant, with the distance $d=1$. The maximal frequency in a spectrum defined in this way is 
$\mathrm{F}=1 / 2 \mathrm{~d}=0.5$. The frequency range is independent of the total number of points in the sequence. The total number of points in a sequence influences only resolution of the spectrum. The resolution of the $\mathrm{N}$-point sequence is $1 / \mathrm{n}$. The $\mathrm{n}$-th point in the spectral function corresponds to a frequency $\mathrm{f}(\mathrm{n})=\mathrm{nf}=\mathrm{n} / \mathrm{N}$. Thus, the initial information defined by the sequence of amino acids can now be presented in the form of the informational spectrum (IS), representing the series of frequencies and their amplitudes.

The IS frequencies correspond to the distribution of structural motifs with defined physicochemical characteristics and are responsible for the biological functions of a protein. When comparing proteins that share the same biological or biochemical function, the ISM technique allows detection of code/frequency pairs that are specific for their common biological properties or which correlate with their specific interactions. This common informational characteristic of sequences can be determined by cross-spectrum or consensus informational spectrum (CIS) analysis. The CIS of $\mathrm{N}$ spectra is obtained by the following equation:

$$
C(j)=\prod_{i=1}^{M} S(i, j), \quad j=1,2, \ldots, N / 2
$$

where $S(i, j)$ is the $j$-th element of the $i$-th power spectrum and $C(j)$ is the $j$-th element of CIS. Thus, the CIS is the Fourier transform of the correlation function for the spectrum. As a result of this method, any spectral component (frequency) not present in all compared ISs is eliminated. Peak frequencies in CIS are common frequency components for the analyzed sequences. A measure of similarity for each peak is a signal-to-noise ratio $(\mathrm{S} / \mathrm{N})$, which represents a ratio between signal intensity at one particular frequency and the main value of the whole spectrum. If one calculates a CIS for a group of proteins that have different primary structures and finds strictly defined peak frequencies, it means that the analyzed proteins participate in mutual interactions or have a common biological function.

The ISM was successfully applied in structure-function analyses of protein sequences, as well as in de novo design of biologically active peptides [33-58].

\section{RESULTS AND DISCUSSION}

Several laboratory and clinical studies have demonstrated the anti-inflammatory, antiatherosclerotic, anti-cancer, and anti-viral activities of pomegranate juice [3-13, 59-66]. However, these studies still leave the question of whether these extraordinary health effects of pomegranate are the consequence of some unique properties of the pomegranate ingredients open to discussion. In order to answer this question, we compared the electronic properties (represented by AQVN and EIIP) of 101 chemical ingredients of pomegranate with the molecular descriptors calculated for 45010644 randomly selected compounds from the PubChem database (Table 2) [15]. The results of this analysis (Fig. 1) revealed that $37.7 \%$ of pomegranate ingredients have AQVN and EIIP values in the intervals 3.2-3.6 and 0.110-0.135 Ry, respectively. In comparison, only 2,207,359 (4.9\%) of analyzed compounds from PubChem have AQVN and EIIP values in this interval range. 

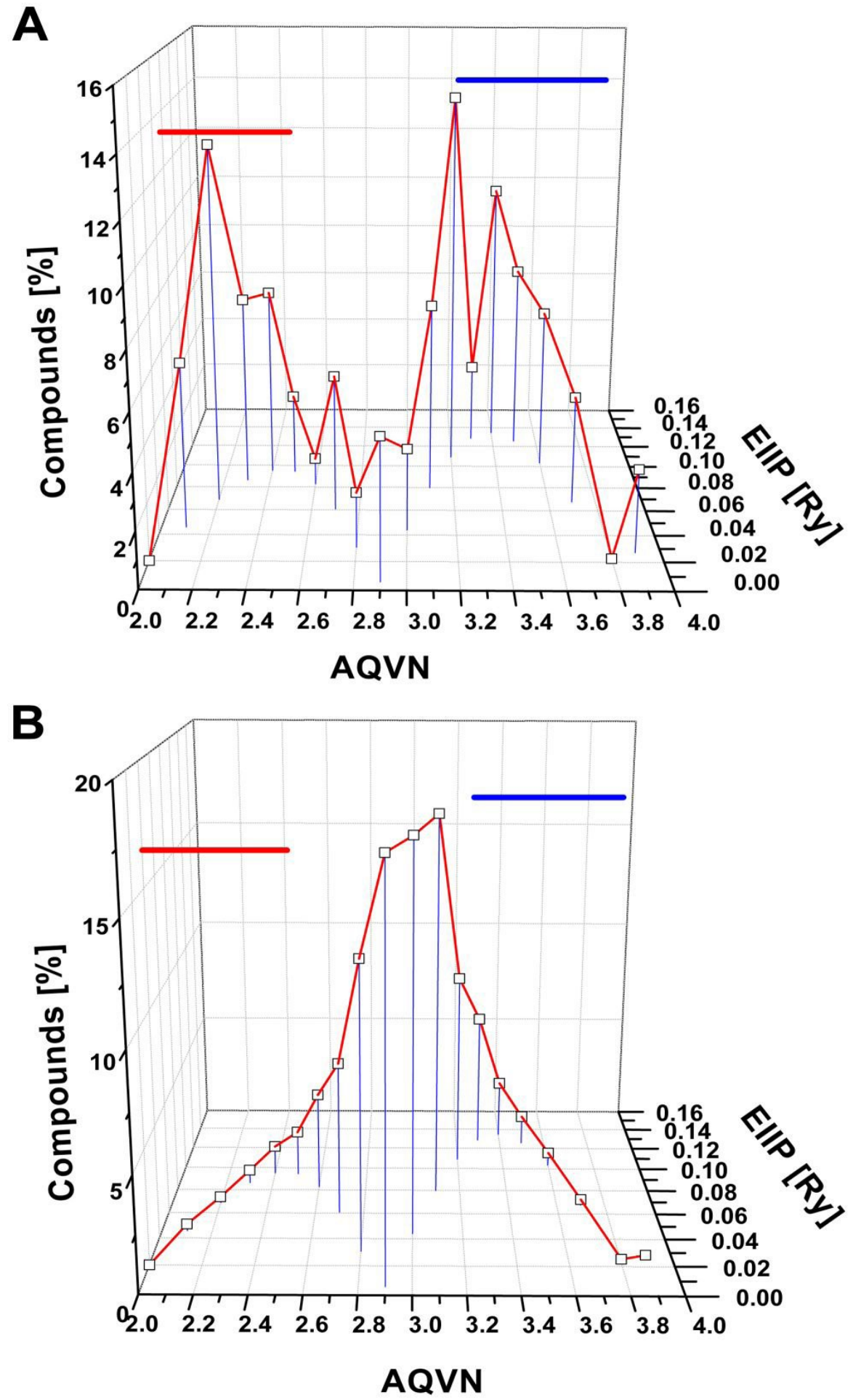

Figure 1. Distribution of chemical compounds in the EIIP/AQVN space: (a) the pomegranate ingredients (Table 2); (b) the compounds from the PubChem database. Domains of the EIIP/AQVN space encompassing electron donors and electron acceptors are marked with red and blue lines, respectively. 
Table 2. The EIIP and AQVN values of the pomegranate ingredients [3]

\begin{tabular}{|c|c|c|c|c|}
\hline Number & Compound name & AQVN & EIIP $[R y]$ & Plant part * \\
\hline 1 & Glucose & 3.000 & 0.0439 & $\mathrm{~J}$ \\
\hline 2 & Fructose & 3.000 & 0.0439 & $\mathrm{~J}$ \\
\hline 3 & Sucrose & 3.022 & 0.0523 & $\mathrm{~J}$ \\
\hline 4 & Citric acid & 3.524 & 0.1218 & $\mathrm{~J}$ \\
\hline 5 & Malic acid & 3.467 & 0.1304 & $\mathrm{~J}$ \\
\hline 6 & Tartaric acid & 3.625 & 0.0954 & $\mathrm{~J}$ \\
\hline 7 & Fumaric acid & 3.667 & 0.0807 & $\mathrm{~J}$ \\
\hline 8 & Succinic acid & 3.286 & 0.1263 & $\mathrm{~J}$ \\
\hline 9 & Ascorbic acid & 3.400 & 0.1344 & $\mathrm{~J}$ \\
\hline 10 & Gallic acid & 3.556 & 0.1150 & $\mathrm{~J}, \mathrm{P}, \mathrm{F}$ \\
\hline 11 & Ellagic acid & 3.929 & 0.0416 & $\mathrm{~J}, \mathrm{P}, \mathrm{S}$ \\
\hline 12 & 3,3'-Di-O-methylellagic acid & 3.588 & 0.1066 & $\mathrm{~S}$ \\
\hline 13 & 3,3',4'-Tri-Omethylellagic acid & 3.460 & 0.1312 & $\mathrm{~S}$ \\
\hline 14 & Caffeic acid & 3.238 & 0.1179 & $\mathrm{~J}, \mathrm{P}$ \\
\hline 15 & Chlorogenic acid & 3.163 & 0.0993 & $\mathrm{~J}$ \\
\hline 16 & $p$-Coumaric acid & 3.100 & 0.0798 & $\mathrm{P}$ \\
\hline 17 & Quinic acid & 3.040 & 0.0588 & $\mathrm{~J}, \mathrm{P}$ \\
\hline 18 & $\begin{array}{l}\text { Brevifolin carboxylic acid 10- } \\
\text { monopotassium sulphate }\end{array}$ & 3.938 & 0.0461 & $\mathrm{~L}$ \\
\hline 19 & Flavan-3-ol & 2.774 & 0.0390 & $\mathrm{~J}, \mathrm{P}$ \\
\hline 20 & Catechin & 3.143 & 0.0934 & $\mathrm{~J}, \mathrm{P}$ \\
\hline 21 & Epicatechin & 3.143 & 0.0934 & $\mathrm{~J}, \mathrm{P}$ \\
\hline 22 & Epigallocatechin 3-gallate & 3.222 & 0.1144 & $\mathrm{~J}, \mathrm{P}$ \\
\hline 23 & Quercetin & 3.500 & 0.1260 & $\mathrm{~J}, \mathrm{P}$ \\
\hline 24 & Kaempferol & 3.419 & 0.1339 & $\mathrm{P}$ \\
\hline 25 & Rutin & 3.206 & 0.1105 & $\mathrm{~J}, \mathrm{P}$ \\
\hline 26 & Kaempferol 3-O-glycoside & 3.269 & 0.1237 & $\mathrm{P}$ \\
\hline 27 & Kaempferol 3-O-rhamnoglycoside & 2.975 & 0.0344 & $\mathrm{P}$ \\
\hline 28 & Luteolin & 3.419 & 0.1339 & $\mathrm{P}$ \\
\hline 29 & Apigenin & 3.333 & 0.1319 & $\mathrm{~L}$ \\
\hline 30 & Luteolin 7-O-glycoside & 3.269 & 0.1237 & $\mathrm{P}$ \\
\hline 31 & Apigenin 4 '- $O-\beta$-glucopyranoside & 3.216 & 0.1130 & $\mathrm{~L}$ \\
\hline 32 & Luteolin 4'-O- $\beta$-glucopyranoside & 3.216 & 0.1130 & $\mathrm{~L}$ \\
\hline 33 & Luteolin 3 '- $O$ - $\beta$-glucopyranoside & 3.216 & 0.1130 & $\mathrm{~L}$ \\
\hline 34 & Luteolin 3'-O- $\beta$ - xylopyranoside & 3.292 & 0.1272 & $\mathrm{~L}$ \\
\hline 35 & Naringin & 3.068 & 0.0690 & $P$ \\
\hline 36 & Delphinidin & 3.423 & 0.1337 & $\mathrm{P}$ \\
\hline 37 & Cyanidin & 3.334 & 0.1327 & $\mathrm{P}$ \\
\hline 38 & Pelargonidin & 3.258 & 0.1218 & $P$ \\
\hline 39 & Cyanidin 3-O-glucoside & 3.226 & 0.1154 & $\mathrm{~J}$ \\
\hline 40 & Cyanidin 3,5 -di- $O$-glucoside & 3.176 & 0.1028 & $\mathrm{~J}$ \\
\hline 41 & Delphinidin 3-O-glucoside & 3.278 & 0.1251 & $\mathrm{~J}$ \\
\hline 42 & Delphinidin 3,5-di- $O$-glucoside & 3.213 & 0.1124 & $\mathrm{~J}$ \\
\hline 43 & Pelargonidin 3-O-glucoside & 3.173 & 0.10 .21 & $\mathrm{~J}$ \\
\hline 44 & Pelargonidin 3,5-di- $O$-glucoside & 3.137 & 0.0916 & $\mathrm{~J}$ \\
\hline 45 & Punicalin & 3.718 & 0.0602 & $\mathrm{P}, \mathrm{L}, \mathrm{B}, \mathrm{R}$ \\
\hline 46 & Punicalagin & 3.774 & 0.0353 & $\mathrm{P}, \mathrm{L}, \mathrm{B}, \mathrm{R}$ \\
\hline 47 & Corilagin & 3.552 & 0.1158 & $\mathrm{P}, \mathrm{L}$ \\
\hline
\end{tabular}




\begin{tabular}{|c|c|c|c|c|}
\hline Number & Compound name & AQVN & EIIP [Ry] & Plant part * \\
\hline 48 & Casuarinin & 3.663 & 0.0820 & $\mathrm{P}$ \\
\hline 49 & Gallagyldilacton & 4.037 & 0.0938 & $\mathrm{P}$ \\
\hline 50 & Pedunculagin & 3.650 & 0.0868 & $\mathrm{P}$ \\
\hline 51 & Tellimagrandin & 3.585 & 0.1074 & $\mathrm{P}$ \\
\hline 52 & Granatin A & 3.679 & 0.0760 & $\mathrm{P}$ \\
\hline 53 & Granatin B & 3.688 & 0.0727 & $\mathrm{P}$ \\
\hline 54 & Punicafolin & 3.486 & 0.1281 & $\mathrm{~L}$ \\
\hline 55 & $1,2,3$-Tri- $O$-galloyl- $\beta-{ }^{4} \mathrm{C} 1$-glucose & 3.478 & 0.1291 & $\mathrm{~L}$ \\
\hline 56 & Punicacortein A & 3.552 & 0.1158 & $\mathrm{~B}, \mathrm{R}$ \\
\hline 57 & Punicacortein B & 3.552 & 0.1158 & $\mathrm{~B}, \mathrm{R}$ \\
\hline 58 & Punicacortein C & 3.748 & 0.0472 & $\mathrm{~B}, \mathrm{R}$ \\
\hline 59 & Punicacortein D & 3.798 & 0.0236 & $\mathrm{~B}, \mathrm{R}$ \\
\hline 60 & $\begin{array}{l}\text { Punigluconin 2,3-di- } O \text {-galloyl-4,6- } \\
(S) \text { - hexahydroxydiphenoylgluconic acid }\end{array}$ & 3.411 & 0.1342 & $\mathrm{~B}, \mathrm{R}$ \\
\hline 61 & Proline & 2.706 & 0.0594 & $\mathrm{~J}$ \\
\hline 62 & Valine & 2.706 & 0.0594 & $\mathrm{~J}$ \\
\hline 63 & Methionine & 2.700 & 0.0609 & $\mathrm{~J}$ \\
\hline 64 & Tryptamine & 2.583 & 0.0856 & $\mathrm{~J}$ \\
\hline 65 & Serotonin & 2.720 & 0.0554 & $\mathrm{~J}$ \\
\hline 66 & Melatonin & 2.727 & 0.0534 & $\mathrm{~J}$ \\
\hline 67 & Peelletierine & 2.320 & 0.0889 & $\mathrm{P}, \mathrm{B}, \mathrm{R}$ \\
\hline 68 & $N$-Methylpelletierene & 2.286 & 0.0843 & $\mathrm{~B}, \mathrm{R}$ \\
\hline 69 & Pseudopelletierene & 2.385 & 0.0947 & $\mathrm{~B}, \mathrm{R}$ \\
\hline 70 & Norpseudopelletierene & 2.435 & 0.0964 & $\mathrm{R}$ \\
\hline 71 & Sedridine & 2.222 & 0.0733 & $\mathrm{R}$ \\
\hline 72 & 2-(2'-Hydroxypropyl $) \Delta^{1}$ - piperideine & 2.269 & 0.0817 & $\mathrm{R}$ \\
\hline 73 & 2-(2'-Propenyll) $\Delta^{1}$ - piperideine & 2.273 & 0.0823 & $\mathrm{R}$ \\
\hline 74 & $\begin{array}{l}N-\left(2^{\prime}, 5^{\prime} \text {-Dihydroxyphenyl) }\right. \\
\text { pyridium chloride }\end{array}$ & 2.269 & 0.0817 & $\mathrm{~L}$ \\
\hline 75 & Hygrine & 2.273 & 0.0823 & $\mathrm{R}$ \\
\hline 76 & Norhygrine & 2.364 & 0.0932 & $\mathrm{R}$ \\
\hline 77 & $\begin{array}{l}\text { Punicic acid (cis-9, trans-11, cis-13 } \\
\text { octadecatrienoic acid) }\end{array}$ & 2.280 & 0.0834 & $\mathrm{~S}$ \\
\hline 78 & Linoleic acid & 2.231 & 0.0749 & $\mathrm{~S}$ \\
\hline 79 & Oleic acid & 2.208 & 0.0704 & $\mathrm{~S}$ \\
\hline 80 & Palmitic acid & 2.160 & 0.0601 & $\mathrm{~S}$ \\
\hline 81 & Stearic acid & 2.143 & 0.0561 & $\mathrm{~S}$ \\
\hline 82 & Daucosterol & 2.283 & 0.0838 & $\mathrm{~S}$ \\
\hline 83 & Camesterol & 2.156 & 0.0591 & $\mathrm{~S}$ \\
\hline 84 & Stigmasterol & 2.173 & 0.0630 & $\mathrm{~S}$ \\
\hline 85 & $\beta$-Sitosterol & 2.150 & 0.0578 & $\mathrm{~S}$ \\
\hline 86 & Cholesterol & 2.194 & 0.0677 & $\mathrm{~S}$ \\
\hline 87 & 17- $\alpha$-Estradiol & 2.455 & 0.0963 & $\mathrm{~S}$ \\
\hline 88 & Estrone & 2.524 & 0.0928 & $\mathrm{~S}$ \\
\hline 89 & Testosterone & 2.367 & 0.0935 & $\mathrm{~S}$ \\
\hline 90 & Estriol & 2.533 & 0.0919 & $\mathrm{~S}$ \\
\hline 91 & $\gamma$-Tocopherol & 2.205 & 0.0699 & $\mathrm{~S}$ \\
\hline 92 & Ursolic acid & 2.296 & 0.0858 & $\mathrm{~S}, \mathrm{~F}$ \\
\hline 93 & Oleanolic acid & 2.308 & 0.0873 & $\mathrm{~F}$ \\
\hline 94 & Maslinic acid & 2.354 & 0.0925 & $\mathrm{~F}$ \\
\hline
\end{tabular}




\begin{tabular}{|c|c|c|c|c|}
\hline Number & Compound name & AQVN & EIIP [Ry] & Plant part * \\
\hline 95 & Asiatic acid & 2.385 & 0.0948 & $\mathrm{~F}$ \\
\hline 96 & Cerebroside & 2.280 & 0.0834 & $\mathrm{~S}$ \\
\hline 97 & Coumestrol & 3.500 & 0.1260 & $\mathrm{~S}$ \\
\hline 98 & $\begin{array}{l}\text { Coniferyl 9- } O \text { - }[\beta-\mathrm{D} \text {-piofuranosyl } \\
(1 \rightarrow 6)]-O-\beta-\mathrm{D} \text {-glucopyranoside }\end{array}$ & 2.952 & 0.0258 & $\mathrm{~S}$ \\
\hline 99 & $\begin{array}{l}\text { Sinapyl 9- } O-[\beta-\mathrm{D} \text {-apiofuranosyl } \\
(1 \rightarrow 6)]-O-\beta-\mathrm{D}-\text { glucopyranoside }\end{array}$ & 2.955 & 0.0269 & $\mathrm{~S}$ \\
\hline 100 & Phenethyl rutinoside & 2.833 & 0.0188 & $\mathrm{~S}$ \\
\hline 101 & Icariside D1 & 2.877 & 0.0028 & $\mathrm{~S}$ \\
\hline
\end{tabular}

* - J: juice, P: leaf, F: flower, L: leaf, S: seed, B: bark of tree, R: bark of tree root

According to the electronic theory of cancer proposed by Albert Szent-Györgyi, cancer is connected with the defective desaturation of the valence band of proteins, and can be inhibited by electron acceptors [67, 68]. Previously, correlations have been reported between EIIP and AQVN of organic molecules and their carcinogenicities [21]. These correlations have been explained by the fact that the electron acceptors are characterized with high EIIP and AQVN values, contrary to the electron donors that have low values for these molecular descriptors [21, 68]. With this perspective, the anti-cancer properties of pomegranate juice could be ascribed to an unusually high content of carcinostaric compounds with high EIIP and AQVN values.

Flavonoids, ellagitannins, anthocyanins, and aliphatic organic acids represent the dominant fraction of pomegranate ingredients with AQVN > 3.2 and EIIP > 0.11Ry. However, the possible molecular mechanisms of action of these compounds must be elucidated before any potential health effects of pomegranate can be reliably predicted. In this study, we performed the ISM analysis on some human proteins representing potential targets of flavonoids. According to the ISM concept, the long-distance recognition and targeting of ligand to a protein is determined by specific information that is encoded in the primary protein structure by the EIIP of their amino acids. This information is represented by the frequencies and corresponding amplitudes in the informational spectrum (IS). Proteins that interact with the same ligand have a common frequency component in their IS.

To identify a characteristic IS frequency representing the information corresponding to specific interactions between flavonoids and proteins, we performed cross-spectral analyses of four quercetin-binding proteins. In Fig. 2a the consensus information spectrum of three flavonol 3-O-methyltransferases 1 from Chrysosplenium americanum (OMT1_CHRAE), Oryza sativa (OMT1_ORYSA), Arabidopsis thaliana (OMT1_ARATH), and flavonol 3-O-methyltransferase 2 from Chrysosplenium americanum (OMT2_CHRAE) are presented.

The dominant peak in the presented CIS indicates that the primary structures of the analyzed flavonol 3-O-methyltransferases encode the same information responsible for their interactions with flavonoids, and this can be represented by their IS frequency $F(0.289)$. To demonstrate this, we multiplied the CIS values of flavonoid 3-O-methyltransferases with IS of flavonol 2,3-dioxygenase from Bacillus subtilis (QDOI_BACSU). The peak in the frequency $\mathrm{F}(0.289)$ in the resulting cross-spectrum (Fig. 2b) strongly indicates that flavonol 2,3dioxygenase shares common information with flavonol 3-O-methyltransferases. In contrast, multiplying the CIS of flavonoid 3-O-methyltransferases with IS of human tryptophan 2,3- 
dioxygenase (BC005355), which does not bind to flavonoids, completely diminished the peak frequency $\mathrm{F}(0.289)$, indicating that this human protein does not share common information with these four flavonoid-binding proteins (Fig. 2c). Consequently, the result of the ISM analysis presented in Fig. 2 suggests that the primary structures of proteins interacting with flavonoids encode specific information that corresponds to IS frequency $\mathrm{F}(0.289)$.

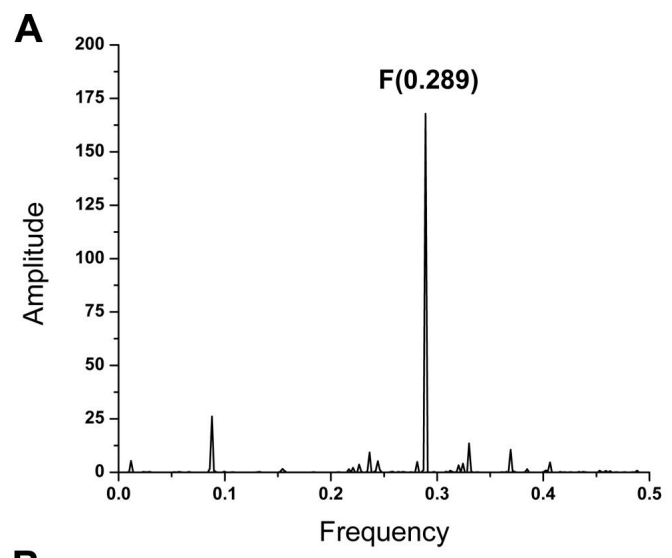

B
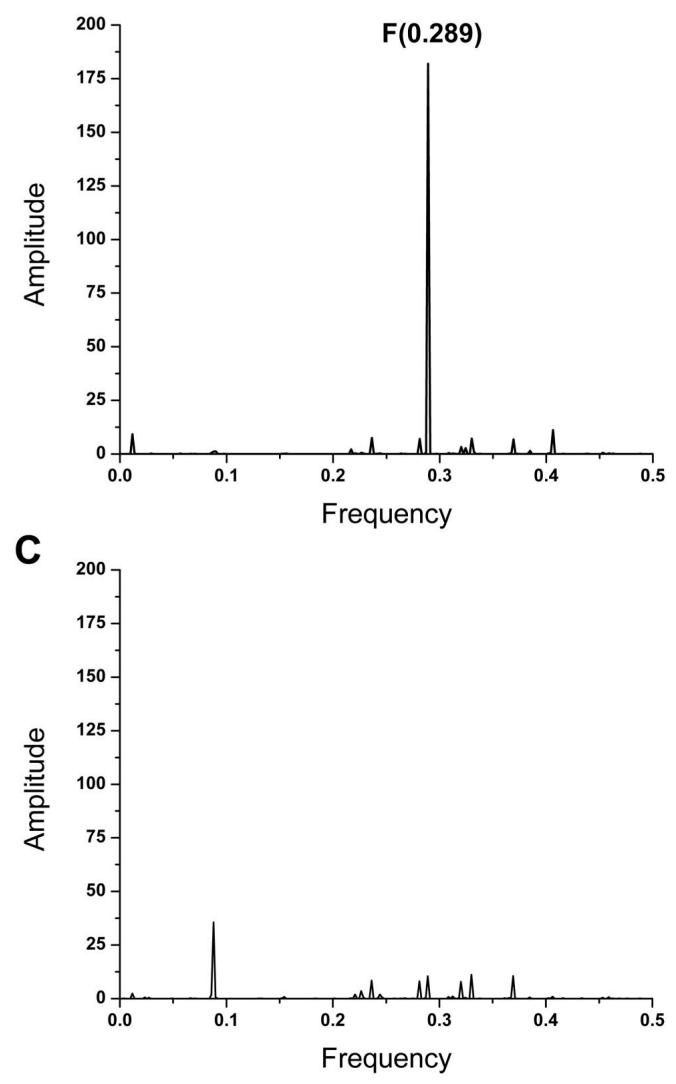

Figure 2. The ISM analysis of flavonoid-binding proteins. (a) CIS of flavonol 3-O-methyltransferases 1. (b) cross-spectrum between CIS of flavonol 3-O-methyltransferases 1 and IS of flavonol 2,3-dioxygenase. (c) crossspectrum between CIS of flavonol 3-O-methyltransferases 1 and IS tryptophan 2,3-dioxygenase. For each spectrum the abscissa represents the frequencies from the Fourier transform of the sequence of electron-ion interaction potential corresponding to the amino-acid sequence of the protein. The lowest frequency is 0.0 and the highest is 0.5. The ordinate represents amplitudes, in arbitrary units, corresponding to each frequency component in the spectrum. 
To identify human proteins that represent the most probable candidates for interactors with flavonoids, we performed ISM analysis of human proteins from the UniProt database. In Table 3 we present 15 human proteins whose IS have a dominant peak on the frequency $F(0.289)$ with the highest amplitude value. Using literature data mined from the PubMed database (www.ncbi.nlm.nih.gov/pubmed), our research revealed that flavonoids are candidates for inhibiting the NF-kappaB (NF-kB) pathway. This finding suggests that among the human proteins that are shown in Table 3, NF-kB represents one of the more likely targets for flavonoids.

Table 3. Human proteins selected as candidate targets of flavonoids.

\begin{tabular}{ll}
\hline Protein & ID \\
\hline Integrator complex subunit 2 (Int2) & INT2_HUMAN \\
MORC family CW-type zinc finger protein 3 & MORC3_HUMAN \\
Angiogenic factor with G patch and FHA domains 1 & AGGF1_HUMAN \\
Putative RNA methyltransferase NCOA6IP & NC6IP_HUMAN \\
PR domain zinc finger protein 1 & PRDM1_HUMAN \\
Lethal(3)malignant brain tumor-like protein & LMBTL_HUMAN \\
Uridine 5'-monophosphate synthase & PYR5_HUMAN \\
Spastin & PAST_HUMAN \\
RING finger protein 103 (Zinc finger protein 103 homolog) & RN103_HUMAN \\
Mucin and cadherin-like protein & MUCDL_HUMAN \\
Nuclear factor NF-kappa-B p65 subunit & TF65_HUMAN \\
Zinc finger protein 683 & ZN683_HUMAN \\
Phenylalanyl-tRNA synthetase & SYFA_HUMAN \\
Oligopeptide transporter, kidney isoform (Peptide transporter 2) & S15A2_HUMAN \\
Serine/threonine-protein kinase PCTAIRE-2 & PCTK2_HUMA \\
\hline
\end{tabular}

However, the fact that flavonoids are not the natural ligand of NF-kB leaves the question of what the functional role of the dominant frequency information encoded in the primary structure of this protein is still open to discussion. The activity of NF-kB is primarily regulated by its interaction with inhibitory IkB proteins. Therefore, a key step for controlling NF-kB activity is the regulation of the $\mathrm{IkB} / \mathrm{NF}-\mathrm{kB}$ interactions. For this reason, we assumed that the information corresponding to IS frequency $\mathrm{F}(0.289)$ is responsible or at least characteristic for the interaction of NF-kB with its principal ligand IkB. To prove this assumption, we performed a cross-spectral analysis of these proteins. As can be seen from results presented in Fig. 3b, the dominant peak in the IkB/NF-kB cross-spectrum is at the frequency $\mathrm{F}(0.289)$.

This strongly suggests that the primary structures of IkB and NF-kB encode the same information which is responsible or at least characteristic for the interactions between these proteins. Because the same information is also responsible for or characteristic of protein/flavonoid interactions, both of these human proteins are potential targets for flavonoids. Although inhibition of the NF-kB pathway by flavonoids is well documented [69-73], the molecular target(s) of these compounds had not been established. Newly-synthesized IkB-alpha can enter the nucleus, remove NF-kB from DNA, and thereby result in the export of the complex back to the cytoplasm. In the classical or canonical pathway, the phosphorylation by IkappaB kinase (IKK) of two specific serines near the N-terminus of IkB-alpha targets this protein for 
ubiquitination and degradation by the $26 \mathrm{~S}$ proteasome. It has been demonstrated that flavonoids inhibit the phosphorylation of IkB by IKK [74-76].
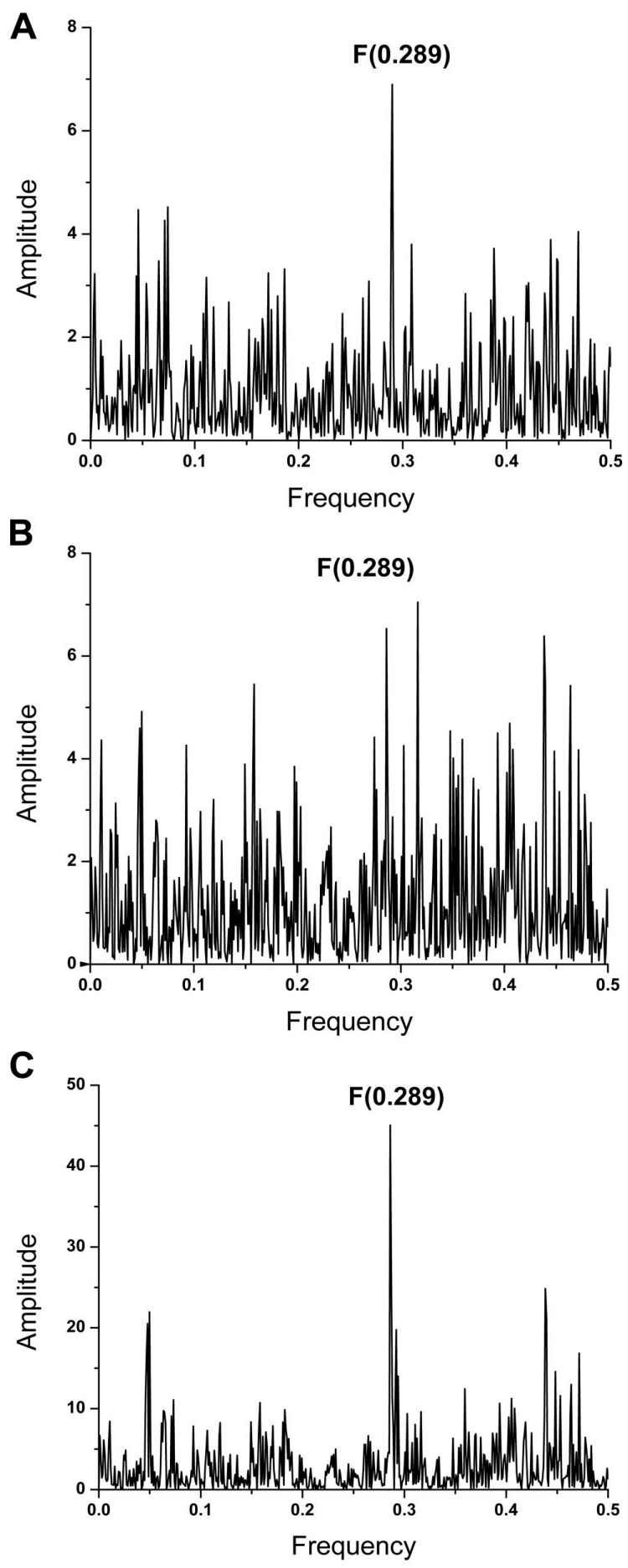

Figure 3. The ISM analysis of NF-kB and IkB-alpha proteins. (a) IS of NF-kB; (b) crosspectrum of NF-kB and IkB-alpha

We hypothesized that this inhibition could be the consequence of the binding of flavonoids to the phosphorylation site of IkB-alpha. A computer scanning survey of the IkB- 
alpha primary structure revealed that the N-terminus of this protein, encompassing residues 1641 , is essential for information represented by the IS frequency $F(0.289)$ (Fig. 3c). It is of interest that this domain contains S32 and S38, which are phosphorylated by IKK. Additionally, it was previously demonstrated that domains which are essential for information determining the longdistance recognition and targeting between a protein and its ligand usually are situated close to their chemical binding sites $[33,34]$. This points out the possibility that flavonoids inhibit the NF-kB pathway by preventing IkB phosphorylation by IKK.

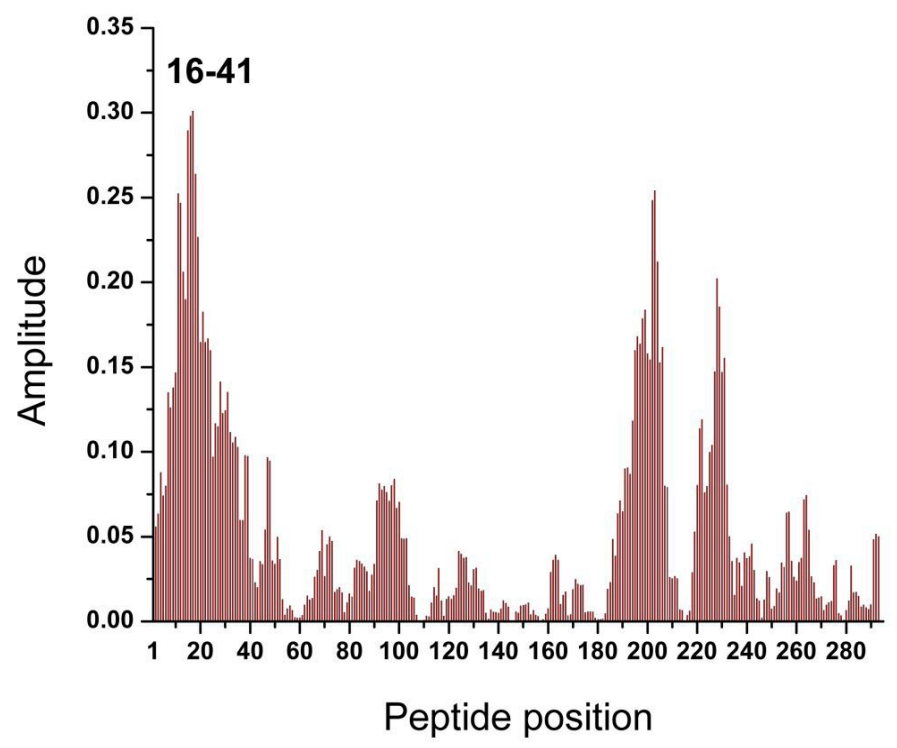

Figure 4. Mapping of the region in IkB interacting with NF-kB

The NF-kB proteins comprise a family of structurally related eukaryotic transcription factors that are involved in the control of a large number of normal cellular processes, such as immune and inflammatory responses, developmental processes, cellular growth, and apoptosis. Additionally, these transcription factors are persistently active in a number of disease states, including cancers, rheumatoid arthritis, chronic inflammation, asthma, neurodegenerative diseases, and heart disease (for a review see Ref. 77). For these reasons, modulation of the NF$\mathrm{kB}$ pathway through inhibition of IkB phosphorylation by flavonoids represents an important potential mode of action of pomegranate ingredients. Inhibition of IkB/IKK interaction by flavonoids provides a rationale framework for designing potent inhibitors of the $\mathrm{IkB}$ phosphorylation site, which is an attractive drug target for inflammatory diseases and cancer.

\section{CONCLUSIONS}

The analysis presented here predicts that flavonoids inhibit the NF-kB pathway by prevention of IkB-alpha phosphorylation. This provides a rationale framework for designing potent new therapeutic compositions of food supplements that target the IkB-alpha phosphorylation site, which is an attractive drug target for inflammatory diseases and cancer. Our results also point out the strong electron-acceptor properties of pomegranate ingredients as an important factor for the anti-cancer activities of pomegranate. We have recently used this type of analysis of electron donor-acceptor characteristics to select potentially active antibiotics for use against multi-drug- 
resistant bacteria [78]. As a result, there appears to be other potential uses of this type of analysis for the development of various new therapeutics.

List of Abbreviations: EIIP, electron-ion interaction potential; AQVN, average quasi valence number; ISM, informational spectrum method; IS, informational spectrum; CS, cross-spectrum; CIS, consensus informational spectrum.

Competing Interests: The authors have no financial interests or conflicts of interest.

Authors' Contributions: All authors contributed to this article.

Acknowledgements and Funding: This work was supported by the Ministry of Education, Science and Technological Development of the Republic of Serbia (Grant no. 173001).

\section{REFERENCES}

1. World Cancer Report 2014, Edited by Stewart BW and Wild CV, IARC, WHO, 2014.

2. 2002 Mortality Data, US Mortality Public Use Data Tape, NCHS, Centers for Disease Control and Prevention, 2004.

3. Lansky EP, Newman RA. Punica granatum (pomegranate) and its potential for prevention and treatment of inflammation and cancer. J Ethnopharmacol. 2007. 109, 177-206.

4. Jeune MA, Kumi-Diaka J, Brown J. Anticancer activities of pomegranate extracts and genistein in human breast cancer cells.J Med Food. 2005.8, 469-75.

5. Kim ND, Mehta R, Yu W, Neeman I, Livney T, Amichay A, Poirier D, Nicholls P, Kirby A, Jiang W, Mansel R, Ramachandran C, Rabi T, Kaplan B, Lansky E. Chemopreventive and adjuvant therapeutic potential of pomegranate (Punica granatum) for human breast cancer. 2002,71, 203-17.

6. Khan N, Hadi N, Afaq F, Syed DN, Kweon MH, Mukhtar H. Pomegranate fruit extract inhibits prosurvival pathways in human A549 lung carcinoma cells and tumor growth in athymic nude mice.Carcinogenesis. 2007 28,163-73..

7. Seeram NP, Adams LS, Henning SM, Niu Y, Zhang Y, Nair MG, Heber D. In vitro antiproliferative, apoptotic and antioxidant activities of punicalagin, ellagic acid and a total pomegranate tannin extract are enhanced in combination with other polyphenols as found in pomegranate juice. J Nutr Biochem. 2005.16,360-7.

8. Kohno H, Suzuki R, Yasui Y, Hosokawa M, Miyashita K, Tanaka T. Pomegranate seed oil rich in conjugated linolenic acid suppresses chemically induced colon carcinogenesis in rats. Cancer Sci.Cancer Sci. 2004. 95, 481-6.

9. Afaq F, Saleem M, Krueger CG, Reed JD, Mukhtar H. Anthocyanin- and hydrolyzable tannin-rich pomegranate fruit extract modulates MAPK and NF-kappaB pathways and inhibits skin tumorigenesis in CD-1 mice. Int J Cancer. 2005. 113,423-33.

10. Malik A, Mukhtar H. Prostate cancer prevention through pomegranate fruit.Cell Cycle. 2006. 5,371-3. 
11. Malik A, Afaq F, Sarfaraz S, Adhami VM, Syed DN, Mukhtar H. Pomegranate fruit juice for chemoprevention and chemotherapy of prostate cancer. Proc Natl Acad Sci U S A. 2005.102,14813-8.

12. Khan GN, Gorin MA, Rosenthal D, Pan Q, Bao LW, Wu ZF, Newman RA, Pawlus AD, Yang P, Lansky EP, Merajver SD. Pomegranate fruit extract impairs invasion and motility in human breast cancer. Integr Cancer Ther. 2009;8:242-253.

13. Albrecht M, Jiang W, Kumi-Diaka J, Lansky EP, Gommersall LM, Patel A, Mansel RE, Neeman I, Geldof AA, Campbell MJ. Pomegranate extracts potently suppress proliferation, xenograft growth, and invasion of human prostate cancer cells. J Med Food. 2004. 7, 274-83.

14. Pantuck AJ, Leppert JT, Zomorodian N, Aronson W, Hong J, Barnard RJ, Seeram N, Liker H, Wang H, Elashoff R, Heber D, Aviram M, Ignarro L, Belldegrun A. Phase II study of pomegranate juice for men with rising prostate-specific antigen following surgery or radiation for prostate cancer.Clin Cancer Res. 2006. 12, 4018-26.

15. http,//pubchem.ncbi.nlm.nih.gov

16. http,//home.ncifcrf.gov/mtdp/Catalog/extracts.html

17. http,//www.uniprot.org

18. Fröhlich, H. Long-range coherence and energy storage in biological systems, Int. J. Quantum Chem. 1968, v.II, 641-649.

19. Fröhlich H.H. Long Range Coherence and the Action of Enzymes. Nature 1970,228,1093.

20. Fröhlich H.H. The extraordinary dielectric properties of biological materials and the action of enzymes. Proc. Natl. Acad. Sci. 1975, 72, 4211-4215.

21. Veljkovic, V. A theoretical approach to preselection of carcinogens and chemical carcinogenesis. Gordon \& Breach, New York, 1980.

22. Veljkovic V, Lalovic D., Theoretical prediction of mutagenicity and carcinogenicity of chemical substances. Cancer Biochem. Biophys. 1976, 1, 295-298.

23. Veljkovic V., Slavic I. Simple general-model pseudopotential. Phys. Rev. Let. 1972, 29, 105-7.

24. Veljkovic V. The dependence of the Fermi energy on the atomic number. Phys. Lett. 1973, 45A, 41-2.

25. Veljkovic V., Lalovic D. General model pseudopotential for positive ions. Phys. Lett. 1973, 45A. 59-60.

26. Veljkovic V, Lalovic D., Simple theoretical criterion of chemical carcinogenesis. Experientia 1977, 33, 1228-9.

27. Veljkovic N, Glisic S, Perovic V, Veljkovic V. The role of long-range intermolecular interactions in discovery of new drugs. Exp. Opin. Drug Disc. 2011;6:1263-70.

28. Veljkovic N, Glisic S, Prljic J, Perovic V, Veljkovic V. Simple and general criterion for "in silico" screening of candidate HIV drugs. Curr Pharm Biotechnol. 2013; 561-9.

29. Veljkovic V, Loiseau PM, Figadere B, Glisic S, Veljkovic N, Perovic VR, Cavanaugh DP, Branch DR. Virtual screen for repurposing approved and experimental drugs for candidate inhibitors of EBOLA virus infection. F1000Res. 2015;4:34 
30. Veljkovic, V., Cosic, I., Dimitrijevic, B., Lalovic, D. it possible to analyze DNA and protein sequences by the methods of digital signal processing? IEEE Trans. 1985;BME32:337-41.

31. Veljkovic V, Cosic I. A novel method of protein analysis for prediction of biological function: application to tumor toxins. Cancer Biochem Biophys. 1987; 9:139-48.

32. Cosic I, Nesic D, Pavlovic M, Williams R. Enhancer binding proteins predicted by informational spectrum method. Biochem Biophys Res Commun. 1986;141:831-8.

33. Cosic, I. The Resonant Recognition Model of Macromolecular Bioreactivity, SpringerVerlag, Berlin, 1997.

34. Veljkovic V., Metlas R., Identification of nanopeptide from HTLV-III, ARV-2 and LAVBRU envelope gp120 determining binding to T4 cell surface protein.Cancer Biochem. Biophys.1988, 10, 91-106.

35. Skerl V., Pavlovic M. Thymopoietins and long postsynaptic neurotoxins share common information in their primary structures.FEBS Lett. 1988, 239, 141-6.

36. Cosic I., Nesic D. Prediction of 'hot spots' in SV40 enhancer and relation with experimental data. Eur. J. Biochem. 1987, 170, 247-52.

37. Cosic I, Pavlovic M, Vojisavljevic V. Prediction of "hot spots" in interleukin-2 based on informational spectrum characteristics of growth-regulating factors. Comparison with experimental data. Biochimie 1989,71, 333-42.

38. Lalovic D, Veljkovic V. The global average DNA base composition of coding regions may be determined by the electron-ion interaction potential. Biosystems. 1990;23:311-6.

39. Cosic I, Hodder AN, Aguilar MI, Hearn MT. Resonant recognition model and protein topography. Model studies with myoglobin, hemoglobin and lysozyme. Eur J Biochem. $1991,198,113-9$.

40. Cosic I, Hearn MT. 'Hot spot' amino acid distribution in Ha-ras oncogene product p21: relationship to guanine binding site. J Mol Recognit. 1991, 4, 57-62.

41. Veljkovic V., Metlas R., Raspopovic J., Pongor S., Spectral and sequence similarity between vasoactive intestinal peptide and the second conserved region of human immunodeficiency virus type 1 envelope glycoprotein (gp120): possible consequences on prevention and therapy of AIDS. Biochem.Biophys.Res. Commun. 1992, 189, $705-$ 10.

42. Cosic I, Drummond AE, Underwood JR, Hearn MT. In vitro inhibition of the actions of basic FGF by a novel 16 amino acid peptide. Mol Cell Biochem. 1994, 130, 1-9.

43. Lazovic J. Selection of amino acid parameters for Fourier transform-based analysis of proteins. Comp. Appl. Bio. Sci.1996, 16, 553-562.

44. Krsmanovic V., Biquard J.M., Sikorska-Walker M., Cosic I., Desgranges C., Trabaurd M.A., Whitfield J.F., Durkin J.P., Achour A., Hearn M.T. Investigations into the crossreactivity of rabbit antibodies raised against nonhomologous pairs of synthetic peptides derived from HIV-1 gp120 proteinsJ Pept Res. 1998, 52, 410-420.

45. Hejase de Trad C, Fang Q, Cosic I. The resonant recognition model (RRM) predicts amino acid residues in highly conserved regions of the hormone prolactin (PRL). Biophys Chem. 2000, 84, 149-57. 
46. Parbhane, R.V., Unniraman, S., Tambe, S.S., Kulkarni, B.D. Optimum DNA curvature using a hybrid approach involving an artificial neural network and genetic algorithm.J. Biomol. Struc. Dyn. 2000, 17, 665-72.

47. Murakami M. Resonant recognition model of neuropeptide Y family: hot spot amino acid distribution in the sequences. J Protein Chem. 2000, 19, 609-13.

48. de Trad CH, Fang Q, Cosic I. Protein sequence comparison based on the wavelet transform approach. Protein Eng. 2002,15, 193-203

49. Veljkovic N, Branch DR, Metlas R, Prljic J, Vlahovicek K, Pongor S, Veljkovic V. J. Design of peptide mimetics of HIV-1 gp120 for prevention and therapy of HIV disease. Pept. Res. 2003, 62, 158-66.

50. Shepherd AJ, Gorse D, Thornton JM. A novel approach to the recognition of protein architecture from sequence using Fourier analysis and neural networks. Proteins. 2003; 50: 290-302.

51. Wen Z, Wang K, Li M, Nie F, Yang Y. Analyzing functional similarity of protein sequences with discrete wavelet transform. Comp. Biol. Chem. 2005, 29, 220-228.

52. Huang J, Tan PH, Li KB, Matsumoto K, Tsujimoto M, Bay BH. Y-box binding protein, YB-1, as a marker of tumor aggressiveness and response to adjuvant chemotherapy in breast cancer. Int J Oncol. 2005, 26, 607-13.

53. Veljkovic N., Perovic V. In silico criterion for prediction of effects of p53 gene missense mutations on p53-Mdm2 feedback loop. Prot. Pep. Lett. 2006, 13, 807-14.

54. Guo, Y.Z, Li, M, Lu, M, Wen, Z, Wang, K, Li, G, Wu, J. Classifying G protein-coupled receptors and nuclear receptors on the basis of protein power spectrum from fast Fourier transform. Amino Acids 2006, 30, 397-402.

55. Veljkovic V, Veljkovic N, Este JA, Huther A, Dietrich U. Application of the EIIP/ISM bioinformatics concept in development of new drugs. Curr. Med. Chem. 2007, 14, 44153

56. Veljkovic V, Glisic S, Veljkovic N, Bojic T, Dietrich U, Perovic VR, Colombatti A. Influenza vaccine as prevention for cardiovascular diseases: possible molecular mechanism. Vaccine 2014; 32:6569-75.

57. Schmier S, Mostafa A, Haarmann T, Bannert N, Ziebuhr J, Veljkovic V, Dietrich U, Pleschka S. In Silico Prediction and Experimental Confirmation of HA Residues Conferring Enhanced Human Receptor Specificity of H5N1 Influenza A Viruses. Sci Rep 2015;5:11434.

58. Bojic T, Perovic V, Glisic S. In silico Therapeutics for Neurogenic Hypertension and Vasovagal Syncope. Front Neurosci 2015;9:520.

59. Mertens-Talcott SU, Jilma-Stohlawetz P, Rios J, Hingorani L, Derendorf H. J Absorption, metabolism, and antioxidant effects of pomegranate (Punica granatum 1.) polyphenols after ingestion of a standardized extract in healthy human volunteers. Agric Food Chem. 2006. 54,8956-61.

60. Jung KH, Kim MJ, Ha E, Uhm YK, Kim HK, Chung JH, Yim SV. Suppressive effect of Punica granatum on the production of tumor necrosis factor (Tnf) in BV2 microglial cells. Biol Pharm Bull. 2006 6, 1258-61. 
61. Adams LS, Seeram NP, Aggarwal BB, Takada Y, Sand D, Heber D. Pomegranate juice, total pomegranate ellagitannins, and punicalagin suppress inflammatory cell signaling in colon cancer cells. J Agric Food Chem. 2006. 54. 980-5.

62. Huang TH, Peng G, Kota BP, Li GQ, Yamahara J, Roufogalis BD, Li Y. Pomegranate flower improves cardiac lipid metabolism in a diabetic rat model: role of lowering circulating lipids. Br J Pharmacol. 2005. 145, 767-74.

63. Aviram M, Rosenblat M, Gaitini D, Nitecki S, Hoffman A, Dornfeld L, Volkova N, Presser D, Attias J, Liker H, Hayek T. Pomegranate juice consumption for 3 years by patients with carotid artery stenosis reduces common carotid intima-media thickness, blood pressure and LDL oxidation. Clin Nutr. 2004. 23, 423-33.

64. Neurath AR, Strick N, Li YY, Debnath AK. Punica granatum (pomegranate) juice provides an HIV-1 entry inhibitor and candidate topical microbicide.Ann N Y Acad Sci. 2005.1056,311-27.

65. Neurath AR, Strick N, Li YY, Debnath AK. Punica granatum (Pomegranate) juice provides an HIV-1 entry inhibitor and candidate topical microbicide. BMC Infect Dis. 2004. 4,41.

66. Li Y, Ooi LS, Wang H, But PP, Ooi VE. Antiviral activities of medicinal herbs traditionally used in southern mainland China. Phytother Res. 2004.18,718-22.

67. Szent-Gyorgyi A. The living state and cancer. Proc Natl Acad Sci U S A. 1977 Jul;74(7):2844-7.

68. Szent-Gyorgyi A. (private communication, PDF of the original letter is available on the request).

69. Comalada M, Camuesco D, Sierra S, Ballester I, Xaus J, Galvez J, Zarzuelo A. In vivo quercitrin anti-inflammatory effect involves release of quercetin, which inhibits inflammation through down-regulation of the NF-kappaB pathway. Eur J Immunol. 2005, 35, 584-92.

70. Kim JS, Jobin C. The flavonoid luteolin prevents lipopolysaccharide-induced NFkappaB signalling and gene expression by blocking IkappaB kinase activity in intestinal epithelial cells and bone-marrow derived dendritic cells.Immunology 2005, 115, 375-87.

71. Singh R, Ahmed S, Islam N, Goldberg VM, Haqqi TM. Epigallocatechin-3-gallate inhibits interleukin-1beta-induced expression of nitric oxide synthase and production of nitric oxide in human chondrocytes: suppression of nuclear factor kappaB activation by degradation of the inhibitor of nuclear factor kappaB. Arthritis Rheum. 2002, 46, 207986.

72. Pan MH, Lin-Shiau SY, Ho CT, Lin JH, Lin JK. Suppression of lipopolysaccharideinduced nuclear factor-kappaB activity by theaflavin-3,3'-digallate from black tea and other polyphenols through down-regulation of IkappaB kinase activity in macrophages. Biochem. Pharmacol. 2000, 59, 357-67.

73. Tsai SH, Liang YC, Lin-Shiau SY, Lin JK. J. Suppression of TNFalpha-mediated NFkappaB activity by myricetin and other flavonoids through downregulating the activity of IKK in ECV304 cells.Cell Biochem. 1999, 74, 606-15. 
74. Peet GW, Li J. IkappaB kinases alpha and beta show a random sequential kinetic mechanism and are inhibited by staurosporine and quercetin. J. Biol. Chem. 1999, 274, 32655-61.

75. Chen JC, Ho FM, Pei-Dawn Lee Chao, Chen CP, Jeng KC, Hsu HB, Lee ST, Wen Tung $\mathrm{Wu}$, Lin WW. Inhibition of iNOS gene expression by quercetin is mediated by the inhibition of IkappaB kinase, nuclear factor-kappa B and STAT1, and depends on heme oxygenase-1 induction in mouse BV-2 microglia. Eur J Pharmacol. 2005, 521, 9-20.

76. Ma Z, Otsuyama K, Liu S, Abroun S, Ishikawa H, Tsuyama N, Obata M, Li FJ, Zheng X, Maki Y, Miyamoto K, Kawano MM. Baicalein, a component of Scutellaria radix from Huang-Lian-Jie-Du-Tang (HLJDT), leads to suppression of proliferation and induction of apoptosis in human myeloma cells. Blood 2005, 105, 3312-8.

77. Beyaert R (editor) (2004). Nuclear Factor-kappaB: Regulation and Role in Disease. Kluwer Academic Publishes, Dordrecht, The Netherlands. 